\title{
Harnessing Text Structure Strategy for Reading Expository and Medical Texts among EFL College Students
}

\author{
Shu-hua $\mathrm{Wu}^{1} \&$ Sulaiman Alrabah ${ }^{1}$ \\ ${ }^{1}$ Language Center, College of Business Studies, Public Authority for Applied Education and Training, Kuwait \\ Correspondence: Shu-hua Wu, Language Center, College of Business Studies, Public Authority for Applied Education \\ and Training, Kuwait.
}

Received: June 9, 2020

Accepted: June 24, 2020

Online Published: June 26, 2020

doi:10.5430/ijhe.v9n5p36

URL: https://doi.org/10.5430/ijhe.v9n5p36

\begin{abstract}
This classroom-based study was conducted in Kuwait to investigate the impact of text structure strategy (TSS) instruction on the ways in which 54 English as a foreign language (EFL) college students approached expository and medical texts. Data collection involved two surveys, fieldnotes, class observations, and group interviews. A system of codes and categories was developed from the recurrent patterns and commonalities in the interview data and classroom observations. Two surveys were distributed in 2 intervals, 8 weeks apart, which focused on identifying text structure strategies such as introducing the concept of text structures, asking guided questions, identifying signaling words, and using graphic organizers, as well as the extent to which the participants applied text structure strategies to approach expository medical texts. Data analysis involved using the Microsoft Excel program to generate two tables and descriptive statistics including the means, standard deviations and percentages of the results of the two surveys. Findings indicated that the participants benefited from TSS instruction in strategies that involved group discussions rather than strategies that relied on individual class work. Moreover, a large percentage of the participants applied most of what they learned in analyzing expository texts into reading medical texts. Implications were drawn for EFL teachers to conduct action research studies on text structure strategy for EFL learners and to apply TSS instruction in class in group and pair work which are suitable for EFL leaners. Finally, EFL researchers were invited to conduct classroom-based studies of TSS instruction.
\end{abstract}

Keywords: text structure strategy, Intelligent Tutoring of the Structure Strategy (ITSS), text structure, expository text, guided question, signaling word, graphic organizer, EFL reading strategy

\section{Introduction}

Several studies in EFL countries have demonstrated that having a high level of reading proficiency in English is highly correlated with overall academic achievement in college (Heeren, Speelman, \& De Wachter, 2020; Stoffelsma \& Spooren, 2019). Therefore, in search for new ways to enhance EFL learners' reading proficiency, text structure strategy (TSS) instruction has been established as a teaching strategy to help learners read expository texts with a high degree of comprehension. Moreover, a number of empirical studies (e.g., Meyer \& Ray, 2017; William, 2018) have found that TSS instruction improved the reading scores of English native speakers and English as a second language (ESL) learners. Similarly, several EFL reading researchers in Asian and Middle Eastern countries have demonstrated the positive effects of teaching text structure strategy to EFL college students (Amiri \& Puteh, 2017; Fan, 2018; Karimpour \& Karkia, 2016).

Text structure strategy refers to the strategy used by readers to approach texts in a strategic manner through closely analyzing different expository texts. More specifically, text structure strategy is concerned with the ways ideas are organized in expository texts, the relationships among ideas, and the vocabulary used to convey meaning to the reader (Pyle et al., 2017). Some researchers (e.g., Roehling, Hebert, Nelson, \& Bohaty, 2017) argued that when students are explicitly taught to identify text structures while they read, they understand the material better and retain more of it after reading. Roehling et al. (2017) explained that knowing the text structure of an expository text may provide the student with a mental framework for comprehending the text. A number of research studies have, moreover, provided evidence that the introduction of TSS instruction in the classroom is pedagogically viable. For example, Roehling et al. (2017), and Williams (2018) have proposed instructional models that included four major strategies in TSS lessons designed to teach students text structure strategy in the classroom. In strategy 1, students were introduced to the concept of text structures. Expository texts are usually organized around five distinct structure 
types including compare-and contrast, problem-and-solution, cause-and-effect, sequence, and description. The purpose of strategy 1 in TSS instruction is to familiarize students with these five text types until they can identify each type in its own right, and distinguish between the ways in which they follow different structures. Next, during strategy 2 , the teacher used guided questions to draw students' attentions to the text type under study. During strategy 2 , the teacher allows adequate time for the student groups, so they can discuss among themselves before they finally raise their hands to answer the guided questions. Strategy 3 taught students to identify the distinctive signaling words that are commonly used by accomplished writers to produce different text types. For example, signaling words such as on the other hand, while, in contrast, conversely, etc. are usually used in the compare-and-contrast text type. Similarly, signaling words such as cause, lead to, bring about, thus, therefore, etc. characterize the cause-and-effect text type. Finally, in strategy 4, the teacher trained the students to map the texts onto the graphic organizers for each text type. For example, the Ven Diagram is used for identifying the compare-and-contrast text type, and the fish bone graphic organizer is used for identifying the cause-and-effect text type.

However, no studies of text structure strategy have been conducted, so far, in Kuwait. Thus, there was a need to conduct the present study to investigate the impact of TSS instruction on the reading abilities of EFL college students. The purpose of the study was twofold: (1) to investigate the impact of text structure strategy on the participants' reading comprehension of expository texts, and (2) to measure the extent to which the participants applied their TSS knowledge to their reading of medical texts. Medical texts were defined in the study as expository texts that contain information about medical topics. The study was conducted to seek answers for the following research questions:

1) How did the four strategies of TSS instruction impact the ways in which the participants approached English expository texts?

2) To what extent have the participants applied the text structure strategies they learned when they approached medical texts?

Findings from this study may add to the existing knowledge base new information about introducing the fledging TSS approach to reading instruction in the English classrooms in the Kuwaiti EFL setting.

\section{Review of the Literature}

This review was organized into three sections. The first section presented studies on introducing TSS instruction in the classroom. The second section explored the integrated Intelligent Tutoring of the Structure Strategy (ITSS) System for TSS instruction. The third section discussed recent text structure strategy studies conducted in EFL contexts to improve the reading abilities of EFL college students.

\subsection{Text Structure Strategy Instruction}

As a pedagogical intervention in English reading classes, a growing body of research studies have suggested that text structure strategy may not only help poor readers' strategy use in terms of dealing autonomously with academic English texts, but it can also empower good readers to become more skilled at comprehending several types of expository texts. Meyer and Ray (2017) identified five different types of texts along with their distinctive signaling words. The five text types were classified according to different purposes such as "compare-and-contrast, problem-and-solution, cause-and-effect, sequence, and description" (p. 129).

Meyer and Ray (2017) further focused on reading instruction with text structure strategy. They found that teachers who gave scant attention during TSS instruction yielded minimal effects of training. For example, when teachers offered simple definitions of text structures along with signaling words and examples of each text type, learners showed minor improvements in reading comprehension and recall. Conversely, when more intensive instruction was offered, including modeling on how to use text structure strategically, strong effects of TSS instruction were reported. Meyer and Ray (2017) suggested that the more teachers focused on teaching text structure by defining and modeling to students how to use text structure, the better learning outcomes were achieved by the students. Furthermore, Beerwinkle, Wijekumar, and Walpole (2018) concluded that there was a general lack among reading teachers in the extent of teacher knowledge about text structure, the extent to which textbooks devoted adequate space to text structure strategy, and teacher instructional practices. They argued that these components practically counteracted the potential benefits of TSS instruction in the classroom. Therefore, in a study that focused on TSS instruction in the classroom, Beerwinkle (2018) investigated the effects of teaching text structure strategy in scientific texts to 7th grade science classrooms with 4 teachers and 169 students in a semi-rural school district in America. The researcher provided the 4 teachers with practice-based professional development on teaching text structure strategy. Results from paired t-tests showed that students significantly improved not only on reading comprehension but also on science knowledge, signaling word knowledge, and main idea quality. Finally, Meyer, Wijekumar, and Lei (2018) 
focused on the effects of TSS instruction on understanding several types of comparative signal words in multi-paragraph expository texts. The study was set in 41 school districts in America with 4th, 5th, 7th, and 8th grade students to examine the effects of instruction of four comparative signal words. Students who were randomly assigned to text structure strategy instruction showed more understanding of comparative signal words than those in the control classrooms.

\subsection{Web-based Text Structure Strategy}

In 2007, Meyer and Wijekumar introduced the Intelligent Tutoring of Structure Strategy (ITSS) system, a web-based delivery system to teach text structure strategy in the classroom. Studies using ITSS have been applied to different populations of learners to monitor the effects of TSS instruction. For example, some researchers (e.g., Meyer, Wijekumar \& Lin, 2011) have developed an individually tailored version of ITSS to match the needs of 5th grade readers by providing them with remediation or enrichment lessons. Moreover, other researchers (e.g., Wijekumar, Meyer, Lei, Beerwinkle, \& Joshi, 2019) targeted a population of 260 4th and 5th grade children who scored below the 25th percentile on comprehension measures using the Gray Silent Reading Test (GSRT). After introducing the ITSS for teaching text structure strategy, the 4th grade students showed small but meaningful effect sizes on the post test. The 5th grade students, moreover, showed moderate to large effects on the post test. Furthermore, Wijekumar, Meyer, and Lei (2017) conducted a large-scale randomized controlled efficacy study on the web-based delivery of the text structure strategy in 108 classrooms of 7th grade students. Classrooms from rural and suburban schools were randomly assigned to either ITSS or control groups. Pretests and posttests were administered at the beginning and end of the school year. Results showed that ITSS classrooms outperformed the control classrooms on all measures of reading comprehension. The latest ITSS version provided children learning text structure strategy with modeling practice, assessment, scaffolding, and feedback on identifying signaling words, summarizing, making inferences, generating elaborations, and monitoring comprehension (Wijekumar et al., 2019).

\subsection{Text Structure Strategy in EFL Settings}

Much of the EFL research on text structure strategy has been done under experimental conditions. For example, Karimpour and Karkia (2016) conducted an experimental study which targeted two groups of female college students majoring in English in Iran in order to explore the potential of TSS instruction to increase EFL students' reading abilities. The researchers reported that the experimental group outperformed the control group on measures of writing content, rhetorical organization, and syntactic complexity. Moreover, Saadatnia, Ketabi, and Tavakoli (2016) conducted an experimental study that compared between EFL students' levels of comprehension across descriptive and enumerative expository text structures. They found that students performed differently after they have been exposed to different text structure types. In addition, Amiri and Puteh (2017) measured student awareness of text structures among two groups of advanced and intermediate EFL students in Malaysia. They found that a general lack of awareness of text structures among EFL learners may cause failure in constructing meaning from academic reading texts. Furthermore, Yeh, Lu, and Humes (2016) investigated whether EFL learners in Taiwan could implicitly learn the text structure of problem-solution without the use of direct (i.e., explicit) instruction. The researchers also investigated the effects of repeated readings of a problem-solution text structure on a sample of $23 \mathrm{EFL}$ students. They found that the advanced level students acquired the text structure of problem-solution in terms of increased awareness from repeated readings while the intermediate group have not shown awareness of the same text structure. Finally, Fan (2018) targeted three groups of 66 Taiwanese EFL university students and exposed them to three different treatments of reading instruction over a period of nine weeks to determine if any of these treatments made a difference in their ability to analyze different text structures. The results showed that the group who benefitted the most was the third group who were trained on metacognitive reading strategies, and at the same time received training and practice on identifying different text structures.

In conclusion, research on text structure strategy has demonstrated considerable potential for improving the reading comprehension of several student populations. Moreover, EFL researchers have highlighted the importance of using text structure strategy to teach expository texts in order to help EFL students increase their reading abilities. However, for mainly logistical reasons, much of the EFL studies on text structure strategy were experimental in design. Yet, for reasons of validity, it is necessary to see how EFL research on text structure strategy can be translated to the classroom. There was a need, therefore, to conduct the present classroom-based study in order to explore the ways in which TSS instruction may impact EFL students' reading comprehension of expository and medical texts. 


\section{Methodology}

The study searched for answers that were focused on the extent to which each of the four strategies of TSS instructional period impacted the ways in which the participants approached expository texts, as well as the extent to which text structure strategies were applied by the participants in reading medical texts. The study was conducted over the fall semester of academic year 2018-2019, and the population were 54 EFL college students. At the onset of the study, the instructor of the English for Specific Purposes (ESP) course, and her two sections of female and male students at the College of Nursing were sent solicitation letters explaining the purpose of the research. The letters contained assurances of confidentiality and anonymity, as well as a special assurance that all the recorded data will only be used for the study. Moreover, all the participants who agreed to join the study were asked to sign "a letter of consent" that also gave them the option of dropping out of the study whenever they chose to do so.

The 54 students were enrolled in two sections of the same ESP course. One section was for female students (N=25), and the other section was for male students $(\mathrm{N}=29)$. The study adopted a longitudinal design in which both ESP sections were taught text structure strategy for expository texts during the first half of the semester. After a period of 8 weeks elapsed, both sections were given the first survey to collect their answers to text structure strategy for expository texts. The second half of the semester was focused, in both sections, on teaching text structure strategy for medical texts. Medical texts were defined in this study as expository texts that contain information about medical topics. After a period of 16 weeks from the beginning of the course, the second survey was distributed to the participants to gauge their responses to text structure strategy for medical texts.

\subsection{Data Collection}

As a "classroom-based research" study (Taber, 2013), the present study systematically utilized multiple data sources including classroom observations, group interviews, fieldnotes, and two surveys. Data collected from the recorded classroom observations and group interviews were transcribed, and a system of codes and categories was developed to identify the recurrent patterns of teaching and learning in the TSS instruction class periods (Bazeley, 2013). After the initial system of codes and categories was revised and corroborated by the two researchers' fieldnotes, a reasonably high degree of agreement between the two researchers was established with almost $95 \%$ consistency. The resultant system of codes and categories was transformed into two "grounded" survey instruments (Strauss \& Corbin, 1997). Survey 1 consisted of 16 items related to the four strategies of TSS instruction in the classroom, and survey 2 consisted of 12 items focused on the extent to which the participants applied the text structure strategies they have learned for reading medical texts. While survey 1 was sent to the participants at the end of the first 8 weeks of the English class, survey 2 was sent at the end of the 16 weeks of the ESP course. Both surveys were uploaded online through Google Forms for the participants of the study. Students responded to each item on a Likert-type scale that ranged from strongly agree, agree, disagree, and strongly disagree. The responses were then encoded to the Microsoft Excel program in order to generate the descriptive statistics including the means, standard deviations, and percentages for each item.

Data were systematically collected over a period of four months. For the first 8 weeks of the ESP course, collected data netted 5 classroom observations that took approximately 20 hours of audiotaped observations with 10 hours per each class. Moreover, to explore the students' perspectives on TSS instruction of both expository and medical texts, the researchers conducted a total of 6 one-hour group interviews with approximately 10 students at a time from each class. "Semi-structured" (Spindler \& Spindler, 1987) interview questions about classroom behaviors and activities in the text structure strategy classroom were derived from the classroom observations and researchers' fieldnotes (Bazeley, 2013). The recorded interviews provided a rich source of data that helped the researchers in the search for commonalities among the participants' responses. The two surveys were largely derived from commonly shared student reactions to TSS instruction of medical texts as well as the four strategies of TSS instruction including text structure concepts, guided questions, signal words, and graphic organizers. Both surveys were distributed among a total of 52 students $(\mathrm{N}=52)$, where $\mathrm{N}$ represented the number of students who responded to the survey. Two students were non-respondents to the surveys, which reduced the total respondent rate to $96.30 \%$.

\subsection{Data Analysis}

A two-pronged approach was utilized in the data analysis stage that included (1) coding and categorizing observation and interview data, and (2) generating descriptive statistics from the survey data. The category system of the TSS lesson as well as the category system of the strategies that helped the students approach medical texts were refined, and an inter-rater reliability check was conducted by the researchers to ensure a high degree of agreement that reached $95 \%$ in terms of assigning participants' utterances to different categories. Responses to the survey items were tabulated on a Microsoft Excel spreadsheet. This program was used to generate descriptive statistics including 
means, standard deviations and percentages for each of the two surveys items. Finally, a total of two tables containing the responses displayed the results for the two research questions of the study.

\section{Results}

The first research question was focused on identifying text structure strategies employed by students during TSS instruction, and the second research question was focused on measuring the extent to which the students applied text structure strategies to read medical texts. The surveys as well as the fieldnotes from classroom observations and group interviews were the main data sources. Results for each of the questions were displayed as tables containing means, standard deviations, and percentages of the relevant survey items along with researchers' fieldnotes for further clarification when needed.

\subsection{The Four Strategies of Text Structure Strategy Instruction}

Research question 1 targeted the ways in which text structure strategies impacted the ways the students approached expository texts. Survey 1 included four strategies that mirrored the progression of the TSS lessons.

Table 1. The four strategies of TSS instruction in the classroom

\begin{tabular}{|c|c|c|c|c|c|}
\hline \multirow{2}{*}{\multicolumn{2}{|c|}{ Text Structure Strategies }} & \multirow{2}{*}{ Mean } & \multirow{2}{*}{ SD } & \multicolumn{2}{|c|}{ Item Responses } \\
\hline & & & & \multirow[t]{2}{*}{ Agree } & \multirow[t]{2}{*}{ Disagree } \\
\hline \multicolumn{4}{|c|}{ Strategy 1. Introducing the Concept of Text Structures } & & \\
\hline 1 & $\begin{array}{l}\text { I benefited when the teacher introduced the concept of text } \\
\text { structures without reading materials. }\end{array}$ & 3.06 & 0.80 & $71.15 \%$ & $28.85 \%$ \\
\hline 2 & $\begin{array}{l}\text { Our teacher explicitly modeled different reading texts from the } \\
\text { simple to the complex to demonstrate different text types. }\end{array}$ & 3.17 & 0.94 & $78.85 \%$ & $21.15 \%$ \\
\hline 3 & $\begin{array}{l}\text { Activating prior knowledge of text structures helped build a } \\
\text { framework for understanding the concept of expository texts. }\end{array}$ & 3.21 & 0.72 & $82.69 \%$ & $17.31 \%$ \\
\hline 4 & $\begin{array}{l}\text { Previewing how texts were organized (e.g., chronologically) } \\
\text { helped to follow the ideas in paragraphs easily. }\end{array}$ & 3.19 & 0.82 & $80.77 \%$ & $19.23 \%$ \\
\hline \multicolumn{6}{|c|}{ Strategy 2. Asking Guided Questions } \\
\hline 5 & $\begin{array}{l}\text { It was useful when the teacher prompted us through asking } \\
\text { guided questions to help us identify the text type under study. }\end{array}$ & 3.69 & 0.61 & $92.31 \%$ & $7.69 \%$ \\
\hline 6 & $\begin{array}{l}\text { Guided questions helped to recognize the structure-related } \\
\text { components of the text type under study. }\end{array}$ & 3.54 & 0.67 & $90.38 \%$ & $9.62 \%$ \\
\hline 7 & $\begin{array}{l}\text { I benefited from pair or group work because I cooperated with } \\
\text { my classmates to confirm or disconfirm the text type. }\end{array}$ & 3.42 & 0.61 & $94.23 \%$ & $5.77 \%$ \\
\hline 8 & $\begin{array}{l}\text { Guided questions trained me to closely analyze several short } \\
\text { paragraphs that demonstrate different text structures. }\end{array}$ & 3.71 & 0.54 & $96.15 \%$ & $3.85 \%$ \\
\hline \multicolumn{6}{|c|}{ Strategy 3. Identifying Signaling Words } \\
\hline 9 & $\begin{array}{l}\text { When I first read a text type, I try to locate the signaling words } \\
\text { that were employed by the writer. }\end{array}$ & 2.85 & 0.70 & $78.85 \%$ & $21.15 \%$ \\
\hline 10 & $\begin{array}{l}\text { Signaling words provided contextual clues and transitions to } \\
\text { understand the ways ideas were presented in a text type. }\end{array}$ & 3.08 & 0.79 & $80.77 \%$ & $19.23 \%$ \\
\hline 11 & $\begin{array}{l}\text { Signaling words like on the other hand, while, in contrast, } \\
\text { similarly, etc. characterize the compare/contrast text type. }\end{array}$ & 2.79 & 0.64 & $76.92 \%$ & $23.08 \%$ \\
\hline 12 & $\begin{array}{l}\text { Signaling words such as cause, lead to, bring about, thus, } \\
\text { therefore, etc. characterize the cause/effect text type. }\end{array}$ & 3.25 & 0.79 & $82.69 \%$ & $17.31 \%$ \\
\hline \multicolumn{6}{|c|}{ Strategy 4. Using Graphic Organizers } \\
\hline 13 & $\begin{array}{l}\text { Graphic organizers provided conceptual frameworks to see the } \\
\text { information globally and figure out the text structure. }\end{array}$ & 3.42 & 0.54 & $94.23 \%$ & $5.77 \%$ \\
\hline 14 & $\begin{array}{l}\text { Every time I read a paragraph, I reduced a paragraph to its } \\
\text { essential details, and I mapped them onto a graphic organizer. }\end{array}$ & 3.50 & 0.67 & $90.38 \%$ & $9.62 \%$ \\
\hline 15 & The fish bone organizer summarized cause-and-effect texts. & 3.62 & 0.63 & $92.31 \%$ & $7.69 \%$ \\
\hline 16 & The Venn Diagram summarized compare-and-contrast texts. & 3.19 & 0.63 & $86.54 \%$ & $13.46 \%$ \\
\hline
\end{tabular}


Table 1 displayed the four major text structure strategies of (1) introducing the concept of text structures, (2) asking guided questions, (3) identifying signaling words, and (4) using graphic organizers for text comprehension. Strategy 1 of the TSS instruction was related to introducing the concept of text structure strategy. The observation notes of each class period indicated that the teacher first introduced the concept of text structures for the students without reading materials to orient themselves to the ways ideas are organized and presented differently for each text type. Next, the class proceeded to strategy 2 in a group discussion format during which the student groups responded to guided questions posed by the teacher, as a form of scaffolding, to try to figure out which of the text types was today's target text structure. Subsequently, the class proceeded to strategy 3 which addressed the signaling words that distinguished the text type under study. Finally, strategy 4 consisted of practice on mapping the ideas and details of the paragraph onto their proper graphic organizers.

\subsubsection{Strategy 1. Introducing the Concept of Text Structures}

Student responses to the survey items showed a reasonable degree of variation. For example, in response to the first item which mentioned that the teacher had a preliminary stage in which the concept of text structure was discussed without explicit use of reading materials, only $71.15 \%$ of the participants agreed that this was really beneficial, while $28.85 \%$ disagreed $(\mathrm{M}=3.06, \mathrm{SD}=0.80)$. The second item in introducing the concept of text structures was related to the teacher's efforts to gradually introduce readings that ranged in their difficulty levels from the simple to the complex. While $78.85 \%$ of the participants agreed this step was helpful in approximating the concept of text structures, $21.15 \%$ disagreed $(\mathrm{M}=3.17, \mathrm{SD}=0.94)$. During the group interviews, the students revealed that they might have needed more practice time to come to grips with the concept of text structures. Therefore, the teacher started to accommodate students by presenting concrete exemplars of well-written paragraphs of the compare-and-contrast text type and the problem-and-solution text type. Item 3 concerned building an approach to reading that included teaching text structure as an organizational component of expository texts. A majority of $82.69 \%$ of the participants responded that they grasped the concept of text structure as a global concept related to the logical presentation of ideas in any given paragraph of expository prose $(\mathrm{M}=3.21, \mathrm{SD}=0.72)$. However, $17.31 \%$ of the participants revealed that they have not begun to think about paragraphs in a global manner when they approached expository text structures. Item 4 was related to orienting students to preview the basic principles of paragraph organization when they approached expository texts. A sizeable majority of $80.77 \%$ of the participants agreed that paying attention to paragraph organization enabled them to read paragraphs because they could follow the writer's line of thought, or succession of ideas were learned more easily than if they did not have the benefit of previewing text organization $(\mathrm{M}=3.19$, $\mathrm{SD}=0.82$ ). A noticeable minority of $19.23 \%$ of the participants did not agree that thinking about paragraph organization was helpful in previewing text structures.

\subsubsection{Strategy 2. Asking Guided Questions}

The second strategy of TSS instruction engaged the teacher and students in a series of guided questions to highlight the text types under study. First, in item 5, a majority of $92.31 \%$ of the participants thought that guided questions helped them to identify different text types $(\mathrm{M}=3.69, \mathrm{SD}=0.61)$. Second, in item 6 , another benefit of the guided questions which was supported by $90.38 \%$ of the participants was related to recognizing the structural components of different text types $(\mathrm{M}=3.54, \mathrm{SD}=0.67)$. Third, in item 7, a majority of $94.23 \%$ of the participants agreed that this activity of asking guided questions was helpful in confirming or disconfirming their respective hypotheses regarding text types $(\mathrm{M}=3.42, \mathrm{SD}=0.61)$. Internally-held beliefs, in effect, get externalized socially, and in the process, everyone publicly gives his/her reasons for why they think so. Fourth, in item 8, a majority of $96.15 \%$ of the participants agreed that the teacher's guided questions helped them in their analysis of different text structure $(\mathrm{M}=3.71, \mathrm{SD}=0.54)$. The teacher used a strategy of giving enough practice opportunities on several short paragraphs that demonstrate different text types. The second strategy of the TSS lesson was deemed helpful by most students because they could exclusively focus on understanding text structures. Each student could individually make a hypothesis or a tentative conclusion about the text types. But when they engage in group or pair discussion, they cooperatively discuss their conclusions either to confirm their hypotheses or adapt new ones.

\subsubsection{Strategy 3. Identifying Signaling Words}

In strategy 3 of TSS instruction, the class teacher introduced signaling words. First, item 9 was made to check whether students incorporated the concept of signaling words into their analysis of text structures. The results showed $78.85 \%$ of the participants agreed that the first items they looked for when they read a text structure were signaling words $(\mathrm{M}=2.85, \mathrm{D}=0.70)$. Nevertheless, $21.15 \%$ of the participants reported that signaling words were not the first item to look for. Item 10 inquired about the perceived benefits of signaling words. While $80.77 \%$ of the participants agreed that signaling words gave them clues about the text type $(\mathrm{M}=3.08, \mathrm{SD}=0.79), 19.23 \%$ disagreed 
that signaling words helped them figure out which text type they were reading. The subsequent items were put to verify whether the students were familiar with the text types of compare-and-contrast, and cause-and-effect. In item 11 , while $76.92 \%$ of the participants recognized the signaling words of the compare-and-contrast text type $(\mathrm{M}=2.79$, $\mathrm{SD}=0.64), 23.08 \%$ reported they did not recognize them. However, in item 12, a majority of $82.69 \%$ of the participants recognized the signaling words that distinguished the cause-and-effect text structure in item $12(\mathrm{M}=3.25$, $\mathrm{SD}=0.79$ ). Only $17.31 \%$ of the participants did not recognize the signaling words of the same structure. In group interviews, students explained the variation between these two items. It was more challenging for them to recognize signaling words in compare/contrast texts when compared to those in cause/effect texts.

\subsubsection{Strategy 4. Using Graphic Organizers}

The fourth strategy of TSS instruction consisted of introducing graphic organizers to depict the schematic organization of different text types. For example, item 13 explored whether graphic organizers provided the conceptual frameworks to help the students read texts to figure out its text structure. The results indicated that $94.23 \%$ of the participants agreed that graphic organizers helped them to look at a paragraph in order to figure out its text structure $(\mathrm{M}=3.42, \mathrm{SD}=0.54)$. Moreover, item 14 showed that $90.38 \%$ of the participants learned to map paragraphs onto graphic organizers every time they approached a text type $(\mathrm{M}=3.50, \mathrm{SD}=0.67)$. In other words, they were able to learn to pre-read and predict which graphic organizer fitted the text type they were reading. However, only $9.62 \%$ of the participants were not sure yet and they needed more practice to read various texts to hone their skills at using graphic organizers. Furthermore, item 15 inquired whether students were able to identify the "fishbone" organizer to depict the ideas of a cause-and-effect text type. While $92.31 \%$ of the participants recognized that the fishbone diagram was used for the cause-and-effect text type, only $7.69 \%$ were not able to recognize it $(\mathrm{M}=3.62$, $\mathrm{SD}=0.63$ ). Finally, item 16 made the same inquiry about whether the "Venn Diagram" or "T-chart" were used as a graphic organizer for the compare-and-contrast text type. While $86.54 \%$ of the participants managed to recognize that the Venn Diagram or T-chart were used as graphic organizers for the compare-and-contrast text type, 13.46\% were not able to make that connection $(\mathrm{M}=3.19, \mathrm{SD}=0.63)$. The interview data further supported the students' variations in using graphic organizers on cause-and-effect and compare-and-contrast text types. When compared to the cause-and-effect text type, the complexity of the compare-and-contrast text type, which involves discussion of two topics, made it challenging for students to map it to its graphic organizer.

\subsection{Utilizing Text Structure Strategies for Reading Medical Texts}

The aim of the second research question was to measure the extent to which text structure strategies were applied by the students when they approached medical texts. Survey 2 tapped students' reactions to different aspects of text structure strategy and the ways in which they influenced students' reading of texts with medical content.

Table 2. Utilizing text structure strategies for reading medical texts

\begin{tabular}{|c|c|c|c|c|c|}
\hline \multirow{2}{*}{\multicolumn{2}{|c|}{ Applying Text Structure Strategies to Approach Medical Texts }} & \multirow{3}{*}{$\begin{array}{l}\text { Mean } \\
3.46\end{array}$} & \multirow{3}{*}{$\begin{array}{l}\text { SD } \\
0.67\end{array}$} & \multicolumn{2}{|c|}{ Item Responses } \\
\hline & & & & \multirow{2}{*}{$\begin{array}{l}\text { Agree } \\
92.31 \%\end{array}$} & \multirow{2}{*}{$\begin{array}{r}\text { Disagree } \\
7.69 \%\end{array}$} \\
\hline 1 & $\begin{array}{l}\text { Prior to TSS instruction, I had difficulty reading medical } \\
\text { texts. }\end{array}$ & & & & \\
\hline 2 & $\begin{array}{l}\text { Learning text structure strategy helped me cope with the } \\
\text { demands of reading specialized medical texts. }\end{array}$ & 3.73 & 0.60 & $90.38 \%$ & $9.62 \%$ \\
\hline 3 & My grasp of medical texts increased due to TSS instruction. & 3.23 & 0.55 & $88.46 \%$ & $11.54 \%$ \\
\hline 4 & $\begin{array}{l}\text { Text structure strategy gave me a background knowledge of } \\
\text { the components of different text types. }\end{array}$ & 3.44 & 0.67 & $\%$ & $\%$ \\
\hline 5 & $\begin{array}{l}\text { The strategies I learned from TSS instruction helped me } \\
\text { become a more efficient reader of medical texts. }\end{array}$ & 3.10 & 0.66 & $86.54 \%$ & $13.46 \%$ \\
\hline 0 & I can recognize medical text types after TSS instruction. & 3.06 & 0.64 & $82.69 \%$ & $17.31 \%$ \\
\hline 7 & Guided questions helped me identify medical text types. & 3.65 & 0.59 & $94.23 \%$ & $5.77 \%$ \\
\hline 8 & $\begin{array}{l}\text { Text-based contextual clues and transitions predicted the } \\
\text { informational content in medical texts. }\end{array}$ & 3.29 & 0.70 & $86.54 \%$ & $13.46 \%$ \\
\hline 9 & I searched for signaling words when reading medical texts. & 2.88 & 0.55 & $80.77 \%$ & $19.23 \%$ \\
\hline
\end{tabular}


10 TSS instruction gave a mental representation of medical texts.

3.62

3.40

3.47
0.60

0.60

0.65
$94.23 \%$

$92.31 \%$

$90.38 \%$
$5.77 \%$

$7.69 \%$

$9.62 \%$ medical texts.

Table 2 provided the students' perspectives on the benefits of TSS instruction when they approached English medical texts. A total of 12 categories were generated from the observation and interview data to describe students' benefits from utilizing text structure strategies for reading medical texts. Table 2 reported the results ranging from the period prior to TSS instruction and the students' perspectives on their reading abilities to the end of the present study, and how they benefited from text structure strategy in reading medical texts.

The results displayed the extent to which the students benefitted from applying the strategies learned during TSS instruction for expository texts to their reading of English medical texts. In item 1, a majority of $92.31 \%$ of the participants agreed that they had difficulty reading and understanding medical texts prior to TSS instruction $(\mathrm{M}=3.46, \mathrm{SD}=0.67)$. Moreover, the majority of the students who participated in the group interviews reported that reading medical texts was a challenge in their academic life. The results for item 2, however, indicated that $90.38 \%$ of the participants agreed that text structure strategies helped them deal effectively with reading medical texts $(\mathrm{M}=3.73, \mathrm{SD}=0.60)$. Moreover, in item 3, a majority of $88.46 \%$ of the participants agreed that they have managed to become more familiar with the technical aspects of medical texts due to the fact that they already learned text structure strategy $(\mathrm{M}=3.23, \mathrm{SD}=0.55)$. Furthermore, in item 4, a majority of $90.38 \%$ of the participants felt that TSS instruction gave them a background knowledge about different text types $(\mathrm{M}=3.44, \mathrm{SD}=0.67)$. This aspect of text structure strategy was deemed useful by the students in handling different types of medical texts. Item 5 was concerned with the students' application and use of text structure strategies in reading medical texts. The results showed $86.54 \%$ of the participants agreed, while $13.46 \%$ disagreed with the basic premise of item 5 that they have become more efficient readers of medical texts $(\mathrm{M}=3.10, \mathrm{SD}=0.66)$.

Learning text structure strategy also impacted the students' familiarity with different text types. In item 6 , while a majority of $82.69 \%$ of the participants agreed that they have become more familiar with different text types, only $17.31 \%$ disagreed with item $6(\mathrm{M}=3.06, \mathrm{SD}=0.64)$. Item 7 was about the extent to which the strategy of asking guided questions helped the students identify the medical text types they were reading. While $94.23 \%$ of the participants agreed that guided questions were beneficial in recognizing text types, only $5.77 \%$ reported that they have not yet learned to benefit from the guided questions strategy in TSS instruction $(\mathrm{M}=3.65, \mathrm{SD}=0.59)$. In item 8, the students were prompted to agree/disagree with the use of contextual clues and transitions to predict the content of medical texts. While $86.54 \%$ of the participants agreed that they used clues and transitions to predict text content, only $13.46 \%$ disagreed with item $8(\mathrm{M}=3.29, \mathrm{SD}=0.70)$.

Moreover, item 9 was concerned about the extent to which the students utilized signaling words to predict the text types of medical readings. While $80.77 \%$ of the participants agreed they utilized signaling words, only $19.23 \%$ disagreed that signaling words helped them predict text types $(\mathrm{M}=2.88, \mathrm{SD}=0.55)$. In item 10 , the results indicated that while $94.23 \%$ of the participants agreed that they were able to formulate a mental representation of the ideas in a text type $(\mathrm{M}=3.62, \mathrm{SD}=0.60)$, only $5.77 \%$ disagreed that they were able to develop a mental representation of text types as a result of TSS instruction. Item 11 focused on the extent to which the students benefitted from the use of graphic organizers as a feature of TSS instruction. While a majority of $92.31 \%$ of the participants agreed that graphic organizers were helpful in summarizing the information in medical English, only 7.69\% disagreed with item 11 $(\mathrm{M}=3.40, \mathrm{SD}=0.60)$. Finally, in item 12 , while graphic organizers helped a majority of $90.38 \%$ of the participants remember the main ideas and supporting details of medical texts, only $9.62 \%$ reported they did not benefit from graphic organizers $(\mathrm{M}=3.47, \mathrm{SD}=0.65)$.

\subsection{Conclusions}

The four strategies of TSS instruction had a variable impact on the ways in which the participants approached expository texts. For example, the second strategy of asking guided questions was seen by most students as beneficial in analyzing the structures of different text types. Moreover, most of the participants also agreed on the importance of utilizing graphic organizers for reading and comprehending expository texts. However, the participants benefitted to a lesser extent from the first strategy of introducing the concept of text structures which aimed to orient them to the ways ideas are organized and presented differently for each text type. Moreover, the participants also reported less benefits in terms of their awareness of the strategy of identifying signaling words in text structure analysis. The data further showed that the participants were able, in varying degrees, to apply the strategies they learned in TSS instruction of 
expository texts to the ways they read medical texts. For example, approximately $83 \%$ of the participants were able to recognize different text types that had medical content. Furthermore, approximately $81 \%$ of the participants were able to identify signaling words when they read medical texts. In sum, the findings of the study indicated that the participants had a degree of variation in terms of the benefits they gained from TSS instruction. The participants also showed variation in the extent to which they applied concepts and strategies learned in TSS instruction to their readings of medical texts.

\section{Implications for EFL Pedagogy}

The present study provided evidence that showed TSS instruction as a viable strategy for improving EFL learners' reading abilities of both expository and medical texts. Therefore, TSS instruction can be conveniently incorporated into the regular reading classes for EFL learners. However, extensive training and practice on teaching text structure strategy are a pre-requisite for teacher training, if this strategy is to bear its fruits for EFL learners. Moreover, EFL teachers can also be trained to use the web-based ITSS application. The study also indicated that EFL learners who participated in the research displayed a general preference for the socially oriented activities in terms of the benefits they gained from the strategies of asking guided questions and using graphic organizers of the TSS lectures. Therefore, there is a need to introduce TSS instruction in the EFL reading classroom, albeit, within a social and cooperative learning atmosphere that may incorporate scaffolding by the teacher, and discussion groups by the students, so they can get the most benefit of TSS instruction. Moreover, the first strategy of introducing the concept of text structures at the beginning of the TSS lesson needs to be done with concrete written examples to avoid the ambiguity and abstractness that may thwart EFL learners' attempts at learning text structure concepts. Moreover, the third strategy of identifying signaling words needs to be done as a group activity in which each group competes with the others to find the right answers for each signaling word. Finally, both textbooks and teacher-developed materials should contain more text structure materials and exercises, so students can practice thoroughly on examples of each text type until they can be in a better position to master text structure strategy.

\section{Implications for Future Research}

Several studies have already made it abundantly clear that TSS instruction was a useful tool for enhancing learners' reading abilities. Nonetheless, there is a need for more research into TSS instructional techniques and their suitability for EFL learners. Moreover, EFL researchers need to conduct more research on the challenges that EFL learners confront when they attempt to read expository texts in English. Furthermore, future studies can investigate the influence of proficiency as a variable that can impede or facilitate the development of text structure strategies across different proficiency levels. There is also a need to conduct studies that compare between the benefits of utilizing web-based intelligent systems that teach text structure strategy and conventional TSS instruction in the classroom. EFL researchers are, moreover, encouraged to conduct classroom-based research into ITSS instruction. The ITSS web-based delivery system showed promise for conducting large scale randomized efficacy-controlled studies across many school districts with students from different grade levels. Therefore, ITSS would be worthy of investigation for EFL reading instructors and researchers in their effort to improve the reading abilities of EFL students. Furthermore, EFL teachers need to conduct their own classroom-based action research (Mertler, 2012) to explore the ways in which text structure strategy can be maximally employed to benefit their students' reading abilities. Both EFL researchers and teachers can, thus, be in a position to add to the existing knowledge base on teaching text structure strategy to EFL college students.

\section{References}

Amiri, F., \& Puteh, M. (2017). Text structure awareness among international students. International Journal of Academic Research in Business and Social Sciences, 7(14), 126-134. http://doi.org/10.6007/IJARBSS/v7-i14/3657

Bazeley, P. (2013). Qualitative data analysis: Practical strategies. Thousand Oakes: Sage Publications.

Beerwinkle, A. L. (2018). A quasi-experimental study of an intervention using the text structure strategy in grade 7 Science (Doctoral dissertation). Texas A\&M University. College Station, TX. http://hdl.handle.net/1969.1/174033

Beerwinkle, A.L., Wijekumar, K., \& Walpole, S. (2018). An analysis of the ecological components within a text structure intervention. Reading and Writing, 31(9), 2041-2064. https://doi.org/10.1007/s11145-018-9870-5

Fan, H. C. (2018). The impact of text structure as a metacognitive mode on EFL learners' reading-to writing. Asian EFL Journal, 20(3), 153-175. Retrieved from http://www.asian-efl-journal.com 
Heeren, J., Speelman, D., \& De Wachter, L. (2020). A practical academic reading and vocabulary screening test as a predictor of achievement in first-year university students: implications for test purpose and use. International Journal of Bilingual Education and Bilingualism, 1-16. http://doi.org/10.1080/13670050.2019.1709411

Karimpour, M., \& Karkia, P. (2016). The impact of summary writing with structure guidelines on EFL college students' rhetorical organization: Integrating genre-based and process approaches. Journal of English Language Pedagogy and Practice, 9(18), 158-182. Retrieved from http://jal.iaut.ac.ir/article_526527.html

Mertler, C. A. (2013). Classroom-based action research: revisiting the process as customizable and meaningful professional development for educators. Journal of Pedagogic Development, 3(3), 38-42. Retrieved from http://hdl.handle.net/10547/335968

Meyer, B. J., \& Ray, M. N. (2017). Structure strategy interventions: Increasing reading comprehension of expository text. International Electronic Journal of Elementary Education, 4(1), 127-152. https://www.iejee.com/index.php/IEJEE/article/view/217

Meyer, B. J., Wijekumar, K., \& Lei, P. (2018). Comparative signaling generated for expository texts by 4th-8th graders: Variations by text structure strategy instruction, comprehension skill, and signal word. Reading and Writing, 31(9), 1937-1968. https://doi.org/10.1007/s11145-018-9871-4

Meyer, B. J., Wijekumar, K. K., \& Lin, Y. C. (2011). Individualizing a web-based structure strategy intervention for fifth graders' comprehension of nonfiction. Journal of Educational Psychology, 103(1), 140. http://doi.org/ $10.1037 / \mathrm{a} 0021606$

Pyle, N., Vasquez, A. C., Lignugaris/Kraft, B., Gillam, S. L., Reutzel, D. R., Olszewski, A., Segura, H., Hartzheim, D., Laing, W., \& Pyle, D. (2017). Effects of expository text structure interventions on comprehension: A meta-analysis. Reading Research Quarterly, 52(4), 469-501. http://doi. org/ 10.1002/rrq.179

Roehling, J. V., Hebert, M., Nelson, J. R., \& Bohaty, J. J. (2017). Text structure strategies for improving expository reading comprehension. The Reading Teacher, 71(1), 71-82. https://doi.org/10.1002/trtr.1590

Saadatnia, M., Ketabi, S., \& Tavakoli, M. (2016). EFL learners' levels of comprehension across text structures: A comparison of literal and inferential comprehension of descriptive and enumerative expository texts. Journal of Psycholinguistic Research, 45(6), 1499-1513. http://dx.doi.org/10.1007/s10936-016-9414-6

Spindler, G., \& Spindler, L. (1987). Issues and applications in ethnographic methods. In G. Spindler \& L. Spindler (Eds.), Interpretive ethnography of education at home and abroad, 1-10. Hillsdale, NJ: Lawrence Erlbaum Associates.

Stoffelsma, L., \& Spooren, W. (2019). The relationship between English reading proficiency and academic achievement of first-year science and mathematics students in a multilingual context. International Journal of Science and Mathematics Education, 17(5), 905-922. https://doi.org/10.1007/s10763-018-9905-z

Strauss, A., \& Corbin, J. M. (Eds.). (1997). Grounded theory in practice. Thousand Oaks, CA: Sage.

Taber, K. (2013). Classroom-based research and evidence-based practice: An introduction (2 $\left.{ }^{\text {nd }} \mathrm{ed}\right)$. Thousand Oaks, CA: Sage Publications.

Wijekumar, K. K., Meyer, B. J., \& Lei, P. (2017). Web-based text structure strategy instruction improves seventh graders' content area reading comprehension. Journal of Educational Psychology, 109(6), 741-760. https://doi.org/10.1037/edu0000168

Wijekumar, K., Meyer, B. J., Lei, P., Beerwinkle, A. L., \& Joshi, M. (2019). Supplementing teacher knowledge using web - based Intelligent Tutoring System for the Text Structure Strategy to improve content area reading comprehension with fourth - and fifth - grade struggling readers. Dyslexia, 15. https://doi.org/10.1002/dys.1634

Williams, J. P. (2018). Text structure instruction: The research is moving forward. Reading and Writing, 31(9), 1923-1935. https://doi.org/10.1007/s11145-018-9909-7

Yeh, L. H., Lu, A. Y. C., \& Humes, K. (2016). Integrating the awareness of text structure into repeated reading intervention: Taiwanese EFL students' reading fluency and reading comprehension. The Asian EFL Journal Quarterly, 18(3), 8-40. Retrieved from http://www.asian-efl-journal.com 